\title{
SIMULASI NUMERIS PERUBAHAN MORFOLOGI DASAR LAUT PADA DESAIN PELABUHAN DI KABUPATEN GRESIK, INDONESIA
}

\author{
Sebrian Mirdeklis Beselly Putra ${ }^{1}$, Agus Suharyanto ${ }^{2}$, Alwafi Pujiraharjo ${ }^{2}$ \\ Jurusan Pengairan Fakultas Teknik Universitas Brawijaya Malang, \\ Jurusan Sipil Fakultas Teknik Universitas Brawijaya Malang \\ e-mails: sebrian@ub.ac.id, agus.s@ub.ac.id, alwafip@gmail.com
}

\begin{abstract}
ABSTRAK : Pengembangan konstruksi Indonesia yang cepat akhir-akhir ini salah satunya dipicu dengan kebijakan tol laut dengan cara pembangunan pelabuhan baru. Salah satunya adalah di Kabupaten Gresik sebagai bongkar barang curah cair dan curah padat. Dibangunnya pelabuhan ini adalah mengurangi beban dan lama tunggu bongkar muat di Tanjung Perak sebagai pelabuhan utama. Besaran lahan reklamasi untuk pelabuhan dan panjang dermaga yang direncanakan akan berhubungan terhadap perubahan morfologi dasar laut. Untuk memahami kondisi tersebut studi dilakukan dengan menggunakan model numeris 2D Coastal Modeling System-Flow (CMS Flow). CMS-Flow menyelesaikannya dengan depth-integrated continuity dan persamaan momentum menggunakan metode volume-hingga. Formula transpor sedimen unified, van Rijn, dan formula transpor non-equilibrium (NET). Pemodelan jangka menengah dijalankan dengan waktu simulasi tiga bulan dengan 5 macam alternatif. Besaran sedimentasi yang minimum di dalam kolam pelabuhan adalah inti dari peninjauan studi. Alternatif yang ketiga dengan desain lolos air memberikan nilai erosi-sedimentasi yang paling kecil, sehingga membuat arus pasang surut dan sungai lebih stabil. Pengembangan dari reklamasi pelabuhan di masa depan disarankan maksimum pada jarak 2700m atau kurang dari garis pantai untuk mencegah turbulensi lebih lanjut.
\end{abstract}

Kata Kunci : Perubahan morfologi, analsis hidrodinamik, alternatif pelabuhan, USACE CMS-Flow

\begin{abstract}
The rapid development of Indonesia leads to Sea Toll Policy by Indonesian government. One of the potential locations is in Gresik Regency as solid and liquid bulk cargo. Purpose of the new harbor is to reduce dwelling time in Tanjung Perak harbor. The amount of land reclamation and the size of the port is strictly related with local sea bed morphological change. This study is conducted using the Coastal Modeling System-Flow (CMS-Flow) 2D numerical model. The unified sediment transport formula, the van Rijn, and a non-equilibrium transport formula (NET) were applied for the computation of sediment transport and morphology change. 5 alternatives medium-term CMS-Flow runs, with simulated times of three months. Minimum sedimentation rate inside harbor is key of the assessment. The chosen alternative model 3 with permeable design gives the lowest rate of erosion and sedimentation that makes tidal and river current are more stable. Development of port reclamation is suggested maximum $2700 \mathrm{~m}$ from the shoreline or less to prevent further turbulences.
\end{abstract}

Key words: Morphological changes, hydrodynamic analysis, harbor alternatives, USACE CMSFlow

Selat Madura adalah bagian dari lalu lintas laut yang penting di bagian timur Indonesia. Perkembangan yang cepat di area Surabaya sebagai pusat pengembangan daerah timur Indonesia telah meningkatkan posisi Selat Madura pada lalu lintas laut, kepentingan domestik, dan fasilitas militer. Reklamasi dan pengembangan pelabuhan adalah salah satu isu besar diantara para pemangku kepentingan dan masyarakat di area ini. Kebutuhan akan analisis yang komprehensif berhubungan 
dengan hidrodinamik dan perubahan morfologi terhadap perkembangan itu dipandang penting. Sejalan dengan perkembangan Selat Madura, Kabupaten Gresik juga berkembang sebagai area baru untuk kontruksi pelabuhan. Dengan posisinya di sebelah utara dari Surabaya sebagai pusat pemerintahan provinsi dan juga perencanaan wilayah GERBANG KERTASUSILA yang akan mengombinasikan kota-kota di sekitar menjadi satu pengembangan dengan Surabaya Raya, Gresik akan memainkan peran penting dan proyek pelabuhan.

Pengembangan pelabuhan diarahkan di Kabupaten Gresik. Tepatnya di Kecamatan Manyar. Tujuan dari dikembangkan pelabuhan ini adalah untuk mengurangi beban dan lama tunggu bongkar muat di Tanjung Perak sebagai pelabuhan utama. Besaran lahan reklamasi untuk pelabuhan dan panjang dermaga yang direncanakan akan berhubungan terhadap perubahan morfologi dasar laut. Selain itu posisi dermaga dan alur pelayaran Selat Madura penting untuk diperhatikan mengingat kepadatan lalu lintas perkapalan di areal tersebut. Untuk memahami respons struktur dan perubahan morfologi dasar laut maka perlu dilakukan analisis dengan menggunakan model numeris. Selanjutnya, analisis transpor sedimen dan perubahan morfologi diperlukan melihat dari alasan di atas. US Army Corps of Engineers Coastal Modeling System (CMS) adalah sebuah sistem pemodelan numeris yang terintegrasi untuk menyimulasikan gelombang laut dangkal, arus, muka air laut, transpor sedimen, dan perubahan morfologi. CMS secara interaktif menghitung transformasi gelombang, dan arus yang diakibatkan gelombang (wave-induced currents), muka air laut akibat pasang surut, angin, dan gelombang, interaksi gelombang-arus, transpor sedimen, dan perubahan morfologi (Sanchez, 2012; Sanchez, 2013; Sanchez, 2011).

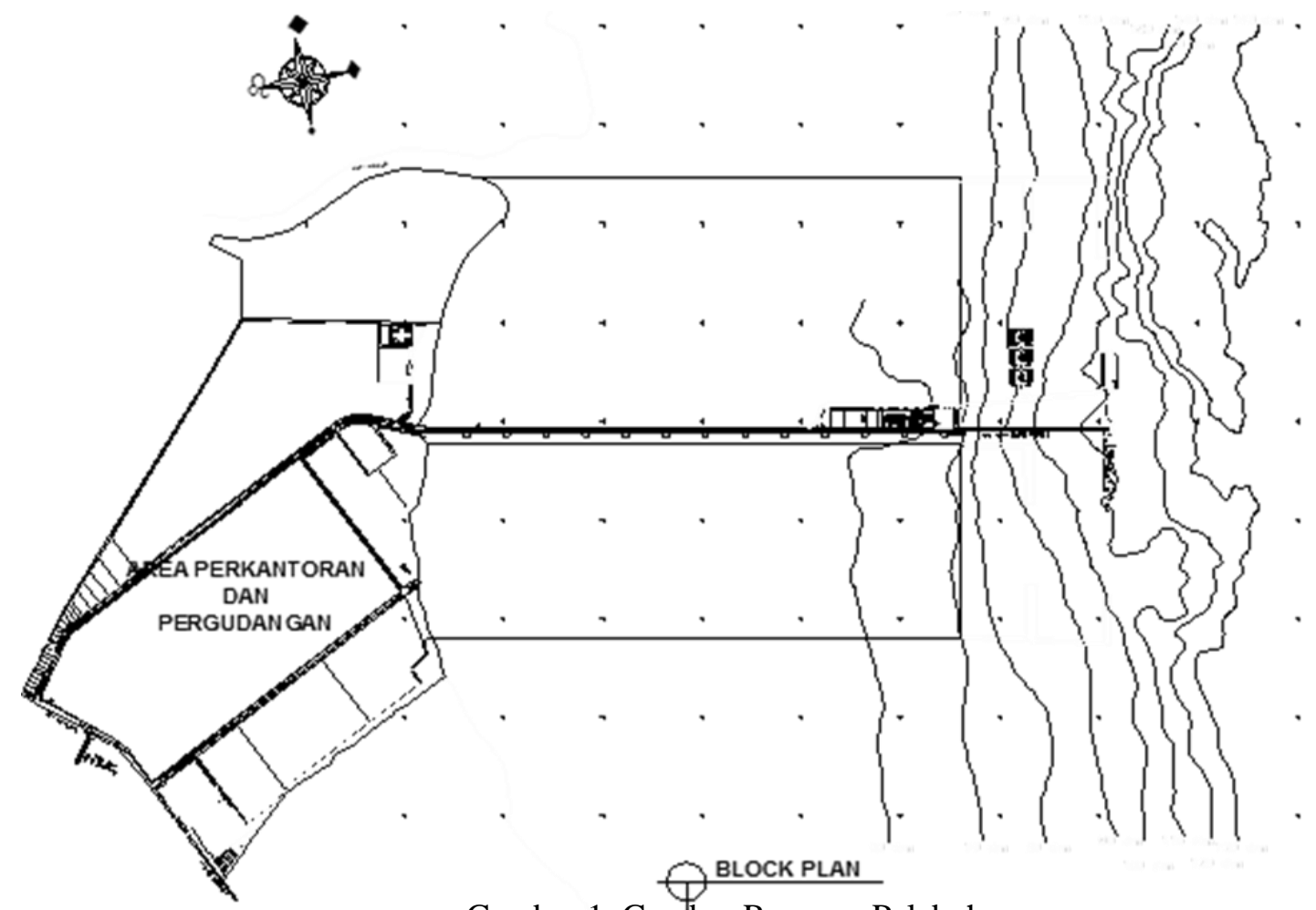

Gambar 1. Gambar Rencana Pelabuhan

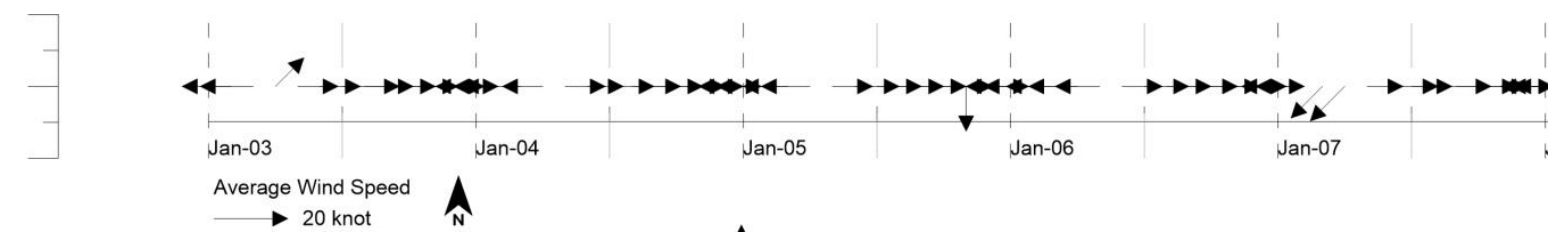

a. analisis plot vektor yang menunjukkan kecepatan angin bulanan rerata (data tahun 2003-2007) 


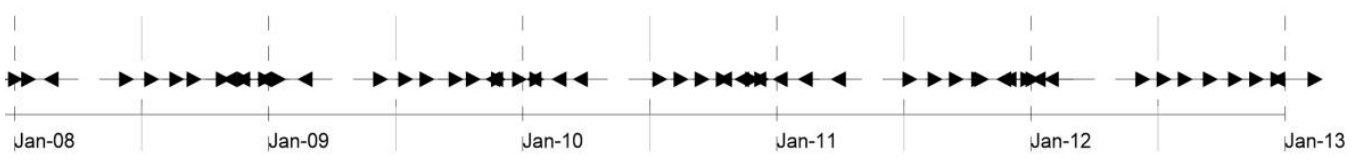

b. analisis plot vektor yang menunjukkan kecepatan angin bulanan rerata (data tahun 2008-2013)

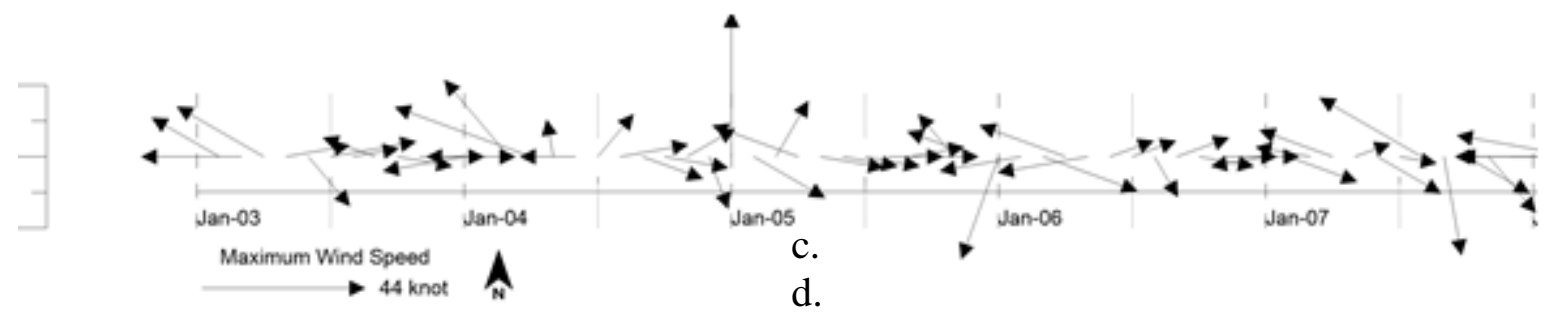

c. analisis plot vektor yang menunjukkan kecepatan angin bulanan maksimum (data tahun 2003-2007)

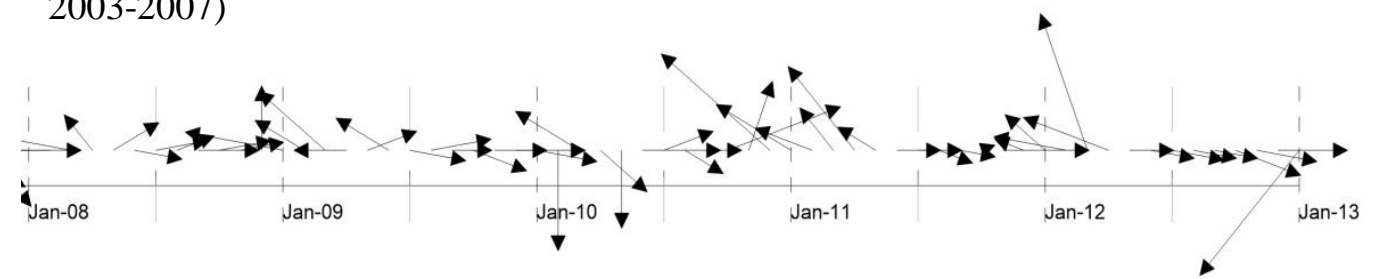

d. analisis plot vektor yang menunjukkan kecepatan angin bulanan maksimum (data tahun 2008-2013)

Gambar 2. Analisis plot vektor yang menunjukkan kecepatan angin bulanan rerata (indeks a dan b) dan kecepatan angin maksimum rerata (indeks $\mathrm{c}$ dan $\mathrm{d}$ )

Grid bathimetri yang baik adalah penting dalam pemodelan teknik pantai, hal ini karena propagasi gelombang dipengaruhi oleh kedalaman bathimetri. Dalam pemodelan dipilih grid numeris dengan tipe telescoping. Grid telescoping dipilih untuk mengoptimalkan sumber daya komputasi. CMS menggunakan multi-level mesh dengan bentuk segi empat quadtree dengan penghalusan lokal. Pada model ini, beberapa level kehalusan grid dibuat secara berangsur dimana grid terkecil pada dekat struktur dan mulut sungai. Local sounding merupakan data primer pada sebuah area $4 \mathrm{~km} \mathrm{x} 4 \mathrm{~km}$ yang meliputi area dari mulut sungai Kali Mireng di selatan hingga tenggara dari area perencanaan pelabuhan. GEBCO (IHO, 2012; IHO, 2012), merupakan tabel bathimetri umum dari lautan yang digunakan sebagai salah satu sumber data pada studi ini selain dari peta lingkungan pantai Indonesia (LPI). Peta daratan sebagian besar diambil dari model elevasi SRTM30.

Wilayah pemodelan (domain) studi dibagi dua yaitu, domain pertama digunakan sebagai kalibrasi dan pengaturan awal disebut sebagai domain persiapan dengan simulasi jangka pendek selama satu bulan. Domain yang kedua disebut sebagai domain simulasi yang digunakan sebagai simulasi jangka menengah selama tiga bulan.

Elevasi muka air dipasang dalam CMSFlow sebagai deret waktu pasang surut (pasut) pada dua batasan; batas laut utara dan laut selatan. Batasan pasut diekstrak dari pendekatan model global pasut Le Provost (Le Provost, 1998).

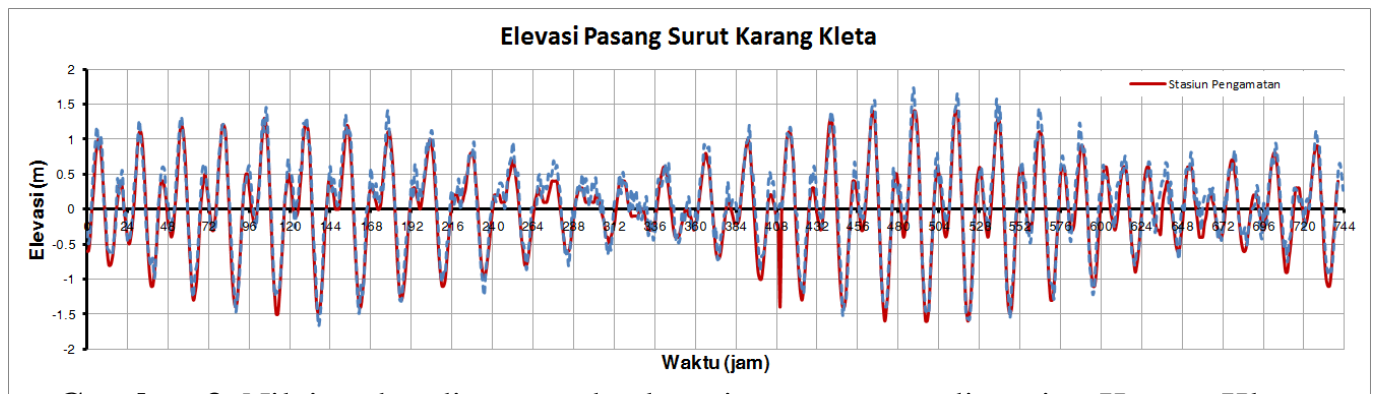

Gambar 3. Nilai perbandingan pada elevasi pasang surut di stasiun Karang Kleta 


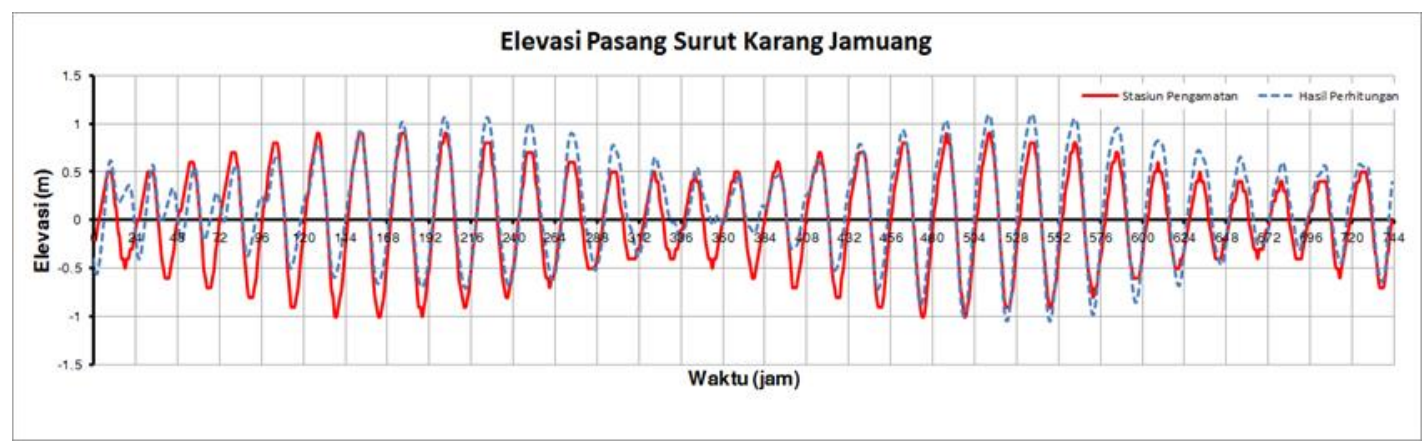

Gambar 4. Nilai perbandingan pada elevasi pasang surut di stasiun Karang Jamuang

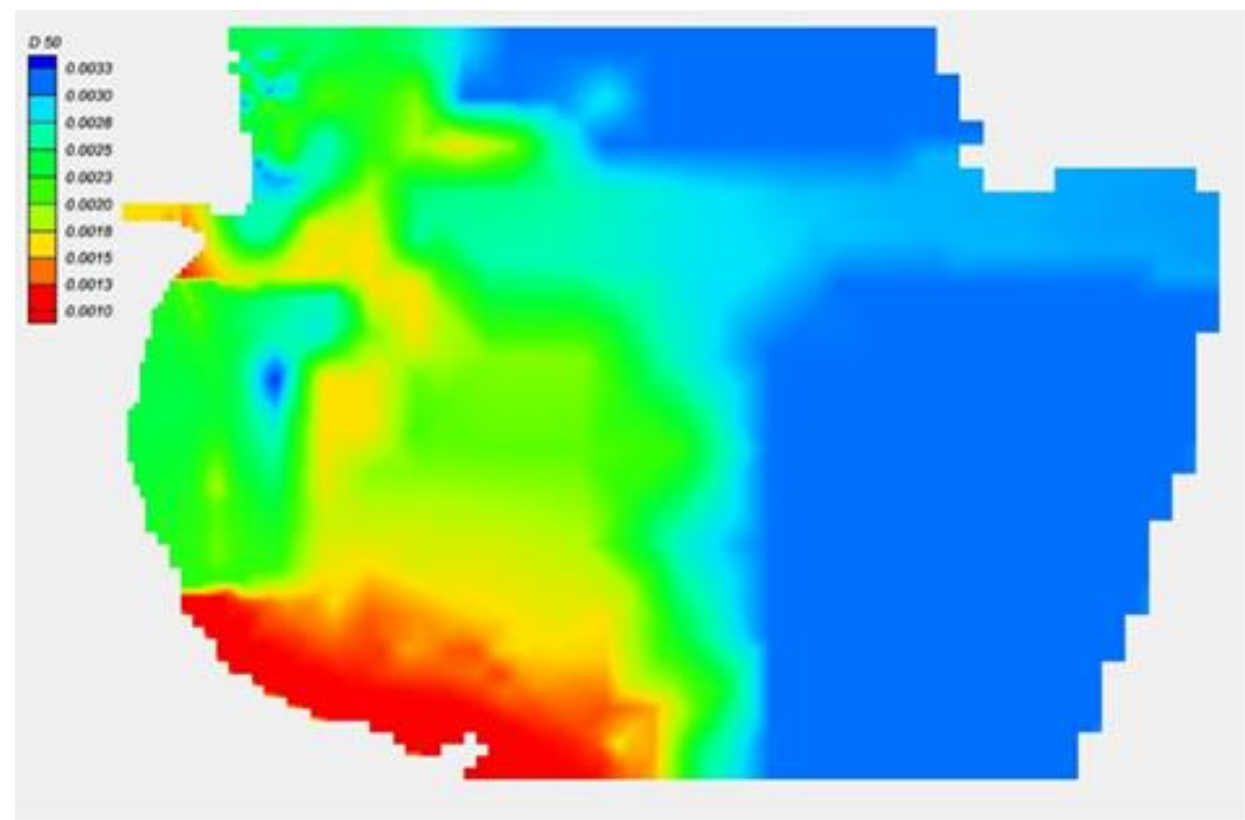

Gambar 5. Kontur diameter butiran sedimen D50 (mm)

Tabel 1. Tabel hasil pengambilan contoh sedimen

\begin{tabular}{|c|c|c|c|c|c|c|}
\hline \multirow{2}{*}{ No. } & \multicolumn{2}{|c|}{ Geographic } & \multicolumn{2}{c|}{ UTM } & \multicolumn{2}{c|}{ Diameter (mm) } \\
\cline { 2 - 7 } & S & E & X & Y & d50 & d90 \\
\hline 1 & 070711.2 & 1123802.0 & 680442 & 9212691 & 0.002 & 0.02 \\
2 & 070718.6 & 1123805.0 & 680533 & 9212464 & 0.002 & 0.022 \\
3 & 070733.9 & 1123744.2 & 679893 & 9211996 & 0.001 & 0.03 \\
4 & 070719 & 1123744.5 & 679905 & 9212454 & 0.001 & 0.06 \\
5 & 070559.1 & 1123754.3 & 680214 & 9214907 & 0.003 & 0.1 \\
6 & 070652.3 & 1123810.6 & 680708 & 9213271 & 0.001 & 0.1 \\
7 & 070647.1 & 1123746.7 & 679975 & 9213434 & 0.001 & 0.08 \\
8 & 070631.4 & 1123739.6 & 679759 & 9213916 & 0.001 & 0.07 \\
9 & 070601.1 & 1123811.8 & 680750 & 9214843 & 0.001 & 0.1 \\
10 & 070556.6 & 1123732.3 & 679539 & 9214986 & 0.001 & 0.1 \\
11 & 070544.6 & 1123758.8 & 680353 & 9215352 & 0.003 & 0.1 \\
12 & 070544.0 & 1123809.1 & 680669 & 9215369 & 0.003 & 0.1 \\
13 & 070628.6 & 1123805.6 & 680557 & 9214000 & 0.001 & 0.1 \\
14 & 070642.9 & 1123807.8 & 680623 & 9213560 & 0.007 & 0.09 \\
\hline
\end{tabular}

Sumber: Hasil pengamatan 
Kemudian hasil model dikalibrasikan dari data observasi stasiun pengamatan Karang Kleta dan Karang Jamuang. Stasiun Karang Kleta berlokasi di $\mathrm{X}=706398,7$ dan $\mathrm{Y}=9190498,2$ sedangkan stasiun pengamatan Karang Jamuang berlokasi di $\mathrm{X}=691015,11$ dan $\mathrm{Y}=$ 923387,32. Koordinat menggunakan sistem UTM atau Universal Transverse Mercator.

Data angin diambil dari BMG Juanda Surabaya. Data tercatat adalah kecepatan dan arah angin bulanan dari Januari 2003 hingga Desember 2012. Arah dan kecepatan tercatat dideskripsikan sebagai plot vektor di Gambar 2 yang menunjukkan angin bulanan rerata dominan dan maksimum berasal dari arah timur.

Debit sungai dipasang sebagai batasan aliran debit. Batasan ini berada di Sungai Mireng sebagai area studi. Debit pada studi ini dihitung dalam bentuk base flow karena kekurangan data jangka panjang dari stasiun pengamatan.

Data sedimen diambil dari proses sampling dari 14 titik survei. Data yang digunakan untuk simulasi adalah diameter butiran D50. Data diameter butiran diambil dari 14 titik pengamatan di sekitar lokasi studi. Data contoh sedimen bisa dilihat pada Tabel 1. Kontur sedimen diberikan pada Gambar 5.

\section{Aplikasi Model \\ Kalibrasi Muka Air}

Untuk mendapatkan hasil yang baik, maka kalibrasi pada model ini dilakukan dalam tiga kasus. Pada dasarnya tiga kasus ini dibagi berdasarkan analisis sensitivitas dengan membandingkan sirkulasi pasang surut dan aliran sungai dengan tambahan interaksi anginarus. Dengan memperhatikan hal tersebut, tiga kasus dapat dideskripsikan sebagai: a) tanpa angin, b) tambahan angin musim hujan, c) tambahan angin musim kemarau.

Lokasi stasiun pengamatan disesuaikan karena batasan dari cakupan domain numeris dan alat ukur pasang surut. Hasil perhitungan variasi muka air dari CMS untuk dibandingkan dengan data observasi ditunjukkan pada Gambar 3. Karena stasiun Karang Kleta berada $11,522 \mathrm{~km}$ tenggara dari stasiun pengamatan, hasil simulasi menunjukkan sedikit perbedaan fase dibandingkan dengan data observasi karena propagasi gelombang dari selatan ke utara.

Konstituen pasang surut yang dihitung dengan CMS-Flow menunjukkan kesamaan yang baik dengan stasiun Karang Kleta. Begitu pula dengan stasiun Karang Jamuang yang ditunjukkan pada Gambar 4.

\section{Analisis Arus}

Aliran konstan yang bekerja pada perairan pantai diduga dikarenakan oleh angin, gradien tekanan atmosfer, debit sungai, density current, arus dari laut terbuka, dll (Yanagi, 1976) disebut sebagai residual current. Residual current bukan hanya valid di muara tetapi juga berlaku sama di lautan. Dalam pandangan proses fisik, beberapa material yang terinjeksi ke dalam lautan akan dipengaruhi oleh arus. Arus memainkan peran penting dalam proses transpor sedimen/ material dan pergerakan air di area pantai (D. S. Kim, 1997).

Pada subbab ini, analisis residual current adalah penting untuk menginvestigasi arus dominan di area studi. Indonesia memiliki dua musim, yaitu musim hujan (OktoberMaret) dan musim kemarau (April-September). Oleh karena itu studi persiapan ini dibagi dalam tiga kasus, yaitu tanpa angin, tambahan angin musim hujan, tambahan angin musim kemarau.

\section{HASIL DAN PEMBAHASAN}

Untuk menganalisis dampak rencana reklamasi terhadap kondisi arus dan sedimentasi, telah dilakukan beberapa macam simulasi dengan domain simulasi yang telah dipersempit hanya di sekitar rencana lokasi reklamasi. Pada tahap awal dilakukan simulasi dengan domain yang besar, di mana kondisi batas adalah stasiun pengukuran Karang Jamuang di Utara dan Karang Kleta di Selatan. Simulasi ini dinamakan simulasi domain awal.

Setelah dilakukan analisi simulasi domain awal, dilakukanlah beberapa analisis simulasi model dengan setting yang sudah didapatkan dari simulasi awal. Untuk menganalisis dampak akibat adanya reklamasi terhadap kondisi saat ini, dianalisis beberapa simulasi dengan alternatif sebagai berikut: 1) Model 1; adalah simulasi sirkulasi arus dan pola sedimentasi pada kondisi saat ini (kondisi eksisting) yaitu sebelum adanya reklamasi; 2) Model 2; adalah simulasi sirkulasi arus dan pola sedimentasi pada kondisi dimana telah ada area reklamasi dan kondisi breakwater terbuat dari struktur impermeable/tidak lolos air; 3) Model 3; seperti Model 2 namun breakwater terbuat dari struktur 
permeable/lolos air; 4) Model 4; adalah simulasi seperti Model 3 namun ditambahkan saluran yang membelah area reklamasi; dan 5) Model 5; adalah simulasi seperti Model 2 namun ditambahkan saluran yang membelah area reklamasi.

Bentuk dan lokasi dari masing-masing alternatif dengan koordinatnya diberikan di

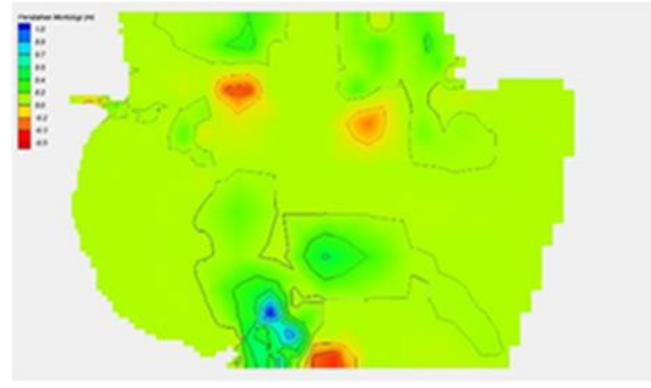

Perubahan Morfologi Model 1

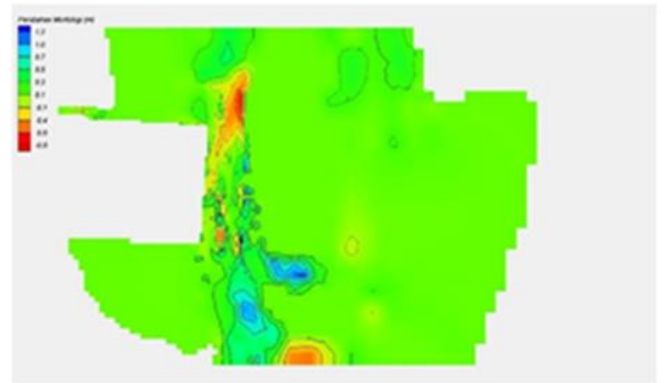

Perubahan Morfologi Model 3

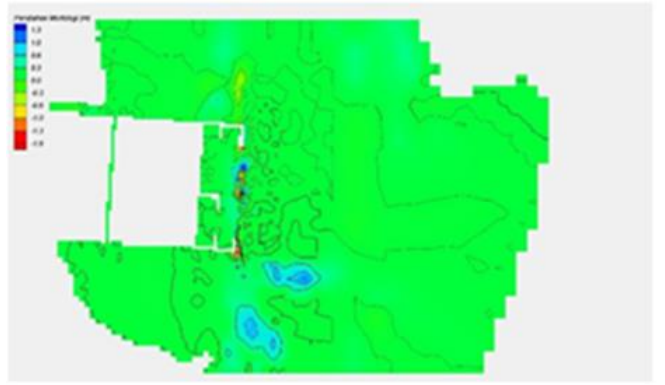

Perubahan Morfologi Model 5
Gambar 6. Gambar ini hanya mendeskripsikan desain eksisting dan tiga alternatif yang diajukan. Model yang lain adalah kondisi eksisting tanpa struktur sebagai referensi untuk pertimbangan hidrodinamik dan perubahan morfologi yang dipakai sebagai acuan pemilihan bentuk reklamasi terbaik dari empat model ya ng diajukan.

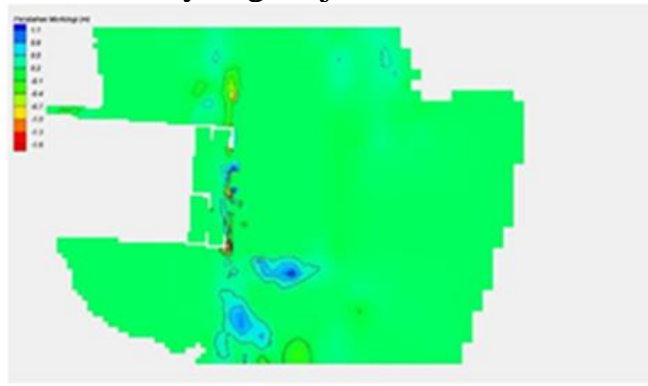

Perubahan Morfologi Model 2

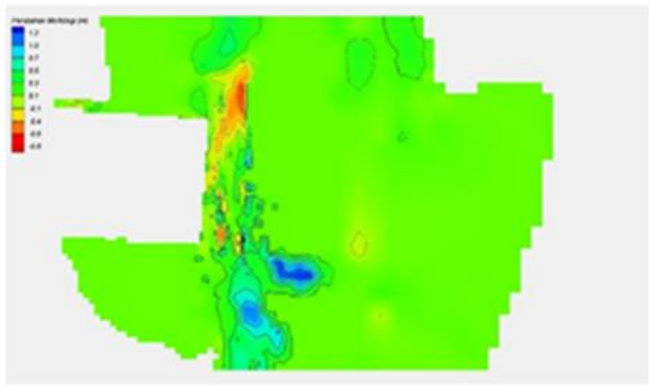

Perubahan Morfologi Model 4

Gambar 6. Kondisi perubahan bathimetri setelah satu tahun simulasi pada 5 model

\section{Hasil Simulasi Model 1}

Simulasi kondisi existing/ model 1 dilakukan sebagai referensi pada model-model yang lainnya. Dengan setting model yang telah diberikan pada domain awal, dilakukan interpretasi terhadap kondisi arus dan pola morfologinya. Seperti dilihat pada Gambar 6, sedimen cenderung terbawa ke laut terbuka dengan perubahan yang terjadi ada pada laut dangkal dekat dengan Kali Mireng yang mengalami perubahan morfologi antara $6 \mathrm{~cm}$ hingga $-7 \mathrm{~cm}$. Hal ini dapat dilihat bahwa keseimbangan dinamis telah tercapai dengan erosi-akresi antara $-7 \mathrm{~cm}$ hingga $6 \mathrm{~cm}$. Kebanyakan sedimen terbilas ke laut dalam/ palung laut di Selat Madura dan terbilas ke arah utara-selatan dari selat.

\section{Hasil Simulasi Model 2}

Pada analisis Model 2 dibuat dengan desain yang telah direncanakan, yaitu pembuatan breakwater impermeable. Desain ini meliputi sejumlah luasan reklamasi pada laut dangkal sepanjang kurang lebih 2700m 
dari garis pantai dengan struktur dermaga yang memanjang kurang lebih $750 \mathrm{~m}$ ke arah timur. Pada analisis domain Model 2 menunjukkan bahwa dengan struktur impermeabel/ padat menyebabkan munculnya turbulensi besar pada ujung-ujung struktur. Struktur dermaga pada Model 1 ini dibuat dengan struktur kaison atau rubble mound. Sehingga dengan kondisi tersebut arus laut terhalang tidak dapat melewati dermaga, maka kemungkinan terganggunya arus dan muncul turbulensi cukup besar. Terjadinya turbulensi akan berakibat pada kecepatan arus besar yang akan membawa material dasar laut yang bisa memicu erosi dan sedimentasi. Dari Gambar 6 ujung dari struktur pelabuhan cenderung mengalami erosi sebanyak $-0,1 \mathrm{~m}$ hingga - 0,4m. Kondisi ini disebabkan karena pada tengah kolam pelabuhan, partikel dasar laut terapung dan menumpuk pada titik maksimumnya hingga $0,8 \mathrm{~m}$. Di mulut sungai Kali Mireng keseimbangan dinamis telah tercapai sekitar $-0,1 \mathrm{~cm}$ hingga $0,2 \mathrm{~m}$. Struktur impermeabel yang besar menunjukkan hasil yang besar dari peningkatan efek turbulensi yang mana meningkatkan proses erosisedimentasi. Pada arah utara-selatan mengalami erosi hingga kedalaman maksimum adalah $0,4 \mathrm{~m}$. Di tengah kolam pelabuhan sedimentasi terjadi pada rasio yang tinggi akibat dari efek turbulensi. Endapan sedimen maksimum yang disimulasikan mencapai $0,8 \mathrm{~m}$.

\section{Potongan Melintang Reklamasi}
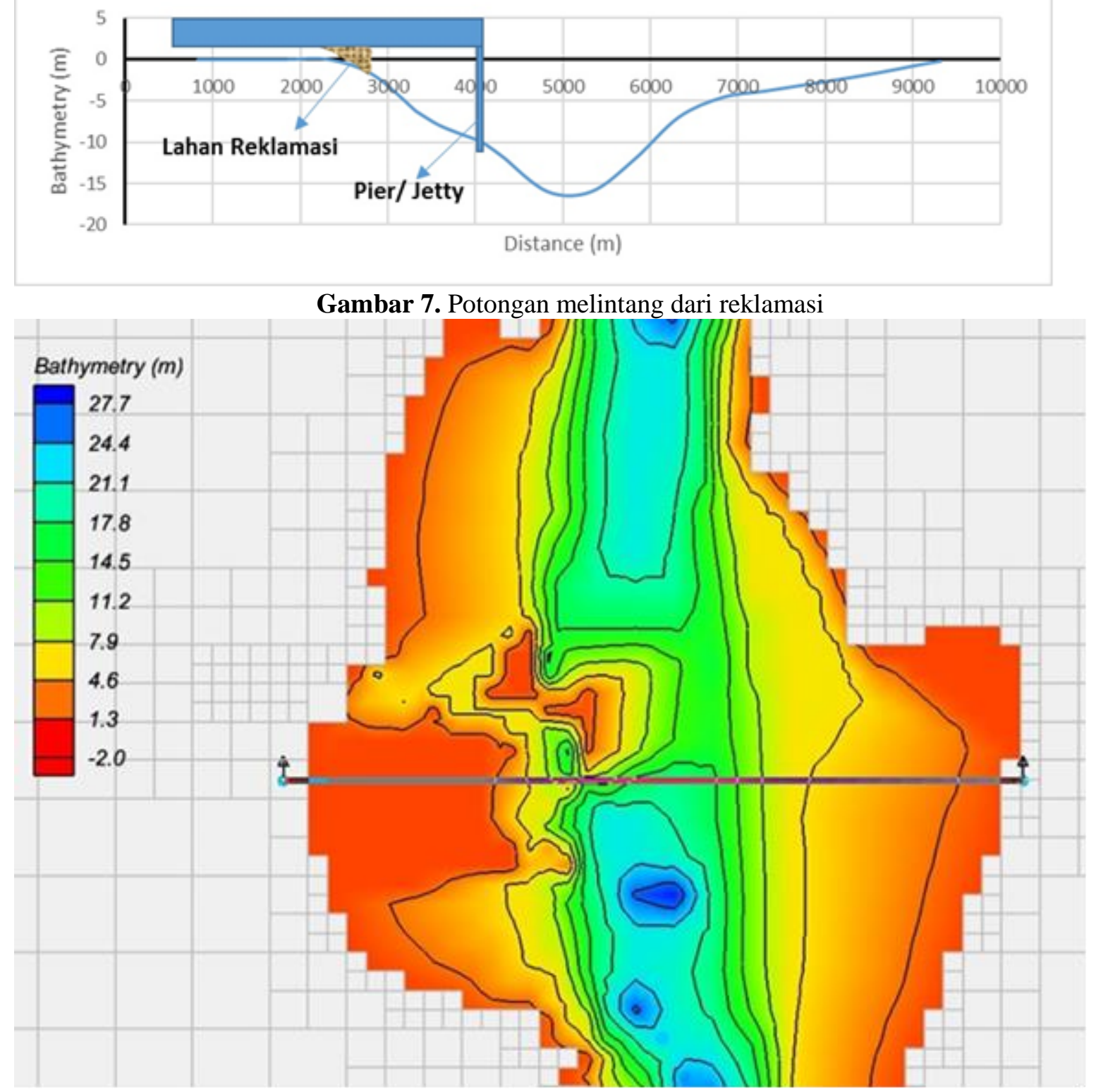

Gambar 8. Lokasi potongan melintang dari reklamasi 


\section{Hasil Simulasi Model 3}

Untuk mengatasi efek turbulensi yang besar di Model 2, Model 3 diusulkan menggunakan struktur permeabel. Seperti ditunjukkan pada Gambar 6, efek erosi dan sedimentasi telah berkurang. Tercatat bahwa besaran erosi dan sedimentasi bervariasi antara $-0,8 \mathrm{~m}$ hingga $1,0 \mathrm{~m}$. Sedimentasi terbesar terletak pada laut dalam hingga ketebalan $1,2 \mathrm{~m}$. Hal ini berarti bahwa arus laut membawa partikel sedimen hingga ke palung laut Selat Madura. Di lokasi kajian Kali Mireng menunjukkan kondisi yang baik dalam keseimbangan dinamisnya.

\section{Hasil Simulasi Model 4}

Pada alternatif ini, sebuah saluran dengan lebar $60 \mathrm{~m}$ ditambahkan untuk memberikan efek bypass transpor sedimen. Saluran ini direncanakan agar sedimen tersebar di dekat garis pantai dan tidak terbawa ke laut dalam. Simulasi ini mencoba untuk melihat efektifitas dari saluran tambahan ini. Pola morfologi terlihat mirip dengan Model 3, terutama di kolam pelabuhan. Dengan saluran melintasi area reklamasi, beberapa dari sedimen dari sungai terbawa ke dalam area reklamasi dengan ketebalan 2-4mm. Berdasarkan dari perspektif teknik pantai, efek yang dihasilkan ini tidak efektif. Jika saluran ini nantinya akan digunakan sebagai navigasi pelayaran, maka bisa digunakan dengan baik.

\section{Hasil Simulasi Model 5}

Pada domain-analisis Model 5 ini dilakukan simulasi dengan kondisi seperti halnya diberikan pada Model 2 tetapi dengan adanya tambahan saluran dengan lebar $60 \mathrm{~m}$ pada tengah-tengah reklamasi dengan tujuan untuk alur kapal nelayan dan diharapkan dapat terjadi bypass transpor sedimen agar tidak terbawa arus ke laut dalam tetapi masih bisa disebarkan di dekat pantai. Hasil simulasi menunjukkan erosi dan sedimentasi antara $1,6 \mathrm{~m}$ hingga $1,3 \mathrm{~m}$. Pola morfologi mirip dengan Model 1 (tanpa saluran navigasi pelayaran). Saluran tambahan yang melintasi area reklamasi tidak memberi banyak kontribusi pada transpor sedimen. Dalam tiga bulan simulasi, ketebalan sedimen di dalam saluran adalah $2-4 \mathrm{~mm}$. Hal ini dikarenakan kecepatan arus terlalu kecil, sehingga kecepatan kritis yang dibutuhkan untuk membawa sedimen tidak tercapai.

\section{KESIMPULAN}

Kesimpulan yang bisa diambil dalam studi ini adalah bisa memberikan kerangka kerja dalam perencanaan kompleks pelabuhan di Kabupaten Gresik berdasarkan perspektif teknik pantai. Peningkatan utama yang menjadi perhatian adalah perubahan morfologi karena bentuk reklamasi dan desain pelabuhan di Kabupaten Gresik dan pengaruh model reklamasi dilihat dari area hasil simulasi.

Analisis arus yang dilakukan untuk jangka pendek dengan mengatur model persiapan pada tiga kondisi; tanpa angin; dengan angin musim hujan; dan angin musim kemarau. Dari ketiga kasus, perbedaan arus yang terjadi tidaklah besar, sekitar 0,005 $\mathrm{m} /$ detik. Maka dapat disimpulkan bahwa komponen utama yang mempengaruhi arus di daerah studi adalah arus pasang surut.

\section{SARAN}

Saran dari simulasi untuk pemerintah melihat dari perspektif teknik pantai adalah untuk memperhatikan lalu lintas kapal di Selat Madura. Akan lebih baik jika konstruksi pelabuhan diundurkan ke elevasi yang cocok untuk draft kapal dan lalu lintas kapal. Disarankan bahwa konstruksi pelabuhan dekat dengan ujung reklamasi, di mana pada elevasi $5 m$ hingga $-6 m$. Dengan kondisi ini stabilitas struktural berdasarkan hidrodinamik bisa tercapai dan kondisi lalu lintas di Selat Madura bisa diatur dengan baik.

\section{DAFTAR PUSTAKA}

A. Sanchez, L. Lin, Z. Demirbilek, T. Beck, M. Brown, H. Li, J. Rosati, W. Wu and C. Reed (2012). Coastal Modelling System Draft User Manual. U.S. Army Engineer Research and Development Center, Coastal and Hydraulics Laboratory, Vicksburg. Vicksburg.

A. Sanchez, W. Wu, H. Li, M. Brown, C. Reed, J. Rosati, Z. Demirbilek and L. Lin (2013). Coastal Modelling System, Report 5: Mathematical Formulations and Numerical Methods. US Army Corps of Engineers Engineer Research and Development Center. Washington DC.

A. Sanchez and W. Wu (2011). A NonEquilibrium Sediment Transport Model for Coastal Inlets and 
Navigation Channels. Journal of Coastal Research. Vol. 59. 39-48.

C. Le Provost, F. Lyard, J. M. Molines, M. L. Genco and F. Rabilloud (1998) A Hydrodynamic Ocean Tide Model Improved By Assimilating A Satellite Altimeter-Derived Data Set. Journal of Geophysical Research. Vol. 103. 5513-5529

D.-S. Kim (1997). Tidal Current and Residual Flow in Suyoung Bay, Korea. Disertasi. Ehime University.

IHO, General Bathymetric Chart of the Oceans (GEBCO) (2012). The GEBCO_08 Grid. IHO. Liverpool.

IHO (2012). The IHO-IOC GEBCO Cook Book. International Hydrographic Organization. Liverpool.
LH (2012). Profil Keanekaragaman Hayati Kota Surabaya Tahun 2012, Surabaya. Badan Lingkungan Hidup Kota Surabaya. Surabaya.

P. Wang, T. M. Beck and T. M. Roberts (2012). Modeling Regional-Scale Sediment Transport and Medium-Term Morphology Change at a Dual-Inlet System Examined with the Coastal Modeling System (CMS): A Case Study at John Pass and Blind Pass, WestCentral Florida. Journal of Coastal Research. Vol. 59. 2.

T. Yanagi (1976). Fundamental Study on The tidal Residual Circulation - I. Journal of the Oceanographical Society of Japan. Vol. 32. 5. 